\title{
Delirium: Prevalence and outcome in the very old in 27 medical departments during a one- year prospective study
}

\section{Original Article}

Cite this article: Marquetand J, Bode L, Fuchs S, Ernst J, von Känel R, Boettger S (2022). Delirium: Prevalence and outcome in the very old in 27 medical departments during a oneyear prospective study. Palliative and Supportive Care 20, 779-784. https://doi.org/ $10.1017 / \mathrm{S} 1478951521001814$

Received: 26 July 2021

Revised: 12 October 2021

Accepted: 31 October 2021

\section{Key words:}

Consultation; Death; Loss of independence; Psychiatric; Risk; Services

\section{Author for correspondence:}

Justus Marquetand, Department of Consultation-Liaison Psychiatry and Psychosomatic Medicine, University Hospital Zurich, University of Zurich, Zurich, Switzerland. E-mail: justus.marquetand@med. uni-tuebingen.de

\author{
Justus Marquetand, M.D. ${ }^{1,2,3,4}$ (D), Leonie Bode, M.D. ${ }^{1}$, Simon Fuchs, M.D. ${ }^{1}$, \\ Jutta Ernst, PH.D. ${ }^{5}$, Roland von Känel, M.D. ${ }^{1}$ and Soenke Boettger, M.D. ${ }^{6}$
}

${ }^{1}$ Department of Consultation-Liaison Psychiatry and Psychosomatic Medicine, University Hospital Zurich, University of Zurich, Zurich, Switzerland; ${ }^{2}$ Department of Epileptology, Hertie-Institute for Clinical Brain Research, University of Tubingen, Tubingen, Germany; ${ }^{3}$ Department of Neural Dynamics and Magnetoencephalography, Hertie-Institute for Clinical Brain Research, University of Tübingen, Tübingen, Germany; ${ }^{4} \mathrm{MEG}$-Center, University of Tübingen, Tübingen, Germany; ${ }^{5}$ Institute of Nursing Science, University Hospital Zurich, University of Zurich, Zurich, Switzerland and ${ }^{6}$ University Hospital Zurich, University Zurich, Zurich, Switzerland

\begin{abstract}
Objective. The prevalence and effects of delirium in very old individuals aged $\geq 80$ years have not yet been systematically evaluated. Therefore, this large single-center study of the one-year prevalence of delirium in 3,076 patients in 27 medical departments of the University Hospital of Zurich was conducted.

Methods. Patient scores on the Delirium Observation Screening scale, Intensive Care Delirium Screening Checklist, Diagnostic and Statistical Manual, 5th edition, and electronic Patient Assessment-Acute Care (nursing tool) resulted in the inclusion of 3,076 individuals in 27 departments. The prevalence rates were determined by simple logistic regressions, odds ratios (ORs), and confidence intervals.

Results. Of the 3,076 patients, 1,285 (41.8\%) developed delirium. The prevalence rates in the 27 departments ranged from $15 \%$ in rheumatology $(\mathrm{OR}=0.30)$ to $73 \%$ in intensive care $(\mathrm{OR}$ $=5.25$ ). Delirious patients were more likely to have been admitted from long-term care facilities $(\mathrm{OR}=2.26)$ or because of emergencies $(\mathrm{OR}=2.24)$. The length of their hospital stay was twice as long as that for other patients. Some died before discharge $(\mathrm{OR}=24.88)$, and others were discharged to nursing homes $(\mathrm{OR}=2.96)$ or assisted living facilities $(\mathrm{OR}=2.2)$.

Conclusion. This is the largest study to date regarding the prevalence of delirium in patients aged $\geq 80$ years and the medical characteristics of these patients. Almost two out of five patients developed delirium, with a high risk of loss of independence and mortality.
\end{abstract}

\section{Introduction}

Delirium (Latin: de and lira, "deviate from a line or furrow") is the most common neuropsychiatric disorder. It is an unspecific, heterogeneous, comorbid brain disorder (Saxena and Lawley, 2009). A key feature is the sudden fluctuating disturbance of consciousness or attention and cognition, as well as emotion, psychomotor activity, and perception (American Psychiatric Association, 2013). Prevalence rates have often been assessed for elderly hospitalized patients aged $\geq 65$ years. Few studies have focused on "very elderly" or "very old" patients, that is, those aged $\geq 80$ years. The current prevalence rates of delirium in the elderly (patients aged $\geq 65$ years) have been determined through cross-sectional designs of admission and incidence rates during or within the first days of hospitalization. They have usually been estimated from pooled data; thus, they are not generalizable to patients aged $\geq 80$ years. In addition, there have been methodological problems, such as a lack of power, smaller sample sizes with no more than a few hundred patients, and a focus on specific patient populations (Inouye et al., 2014).

A single-day point prevalence-study of 311 adult patients in an acute hospital setting found that in 69 patients aged $>80$ years, the delirium prevalence rate was $34.8 \%$ (Bellelli et al., 2016). A retrospective evaluation of 2 years of data on 1,797 cardiac surgical patients aged $>65$ and $>80$ years (Kotfis et al., 2018) found that 230 were $>80$ years old and $33.5 \%$ developed postoperative delirium. In addition to age, seven independent risk factors for developing postcardiac surgery delirium were identified: diabetes, elevated creatinine, pneumonia, extracardiac arteriopathy, prolonged hospitalization time, and postoperative atrial fibrillation.

A review of the literature indicated the need for studies on the prevalence of delirium in individuals aged $\geq 80$ years. Many studies have documented the prevalence rates of and risk factors for delirium in patients aged $>65$ or $>75$ years. In these age groups, the rates and risk factors have been found to vary by department, such as medical, surgical, and intensive 
Table 1. Sociodemographic and medical characteristics of patients with and without delirium

\begin{tabular}{|c|c|c|c|c|c|c|c|}
\hline & \multicolumn{2}{|c|}{$\begin{array}{l}\text { Patients with } \\
\text { delirium }(n=1,285)\end{array}$} & \multicolumn{2}{|c|}{$\begin{array}{l}\text { Patients without } \\
\text { delirium }(n=1,791)\end{array}$} & \multirow{2}{*}{$\begin{array}{c}p \\
<0.001\end{array}$} & \multirow{2}{*}{$\begin{array}{l}\text { OR } \\
- \\
-\end{array}$} & \multirow[t]{2}{*}{$\mathrm{Cl}$} \\
\hline Age in years ${ }^{a}$ & \multicolumn{2}{|c|}{$86,3.98 / 85,6$} & \multicolumn{2}{|c|}{$85.3,3.68 / 84,6$} & & & \\
\hline Gender & in $\%$ & $n$ & in $\%$ & $n$ & & & \\
\hline Male & 52 & 668 & 47 & 842 & 0.548 & 1.05 & $0.9-1.23$ \\
\hline Female & 48 & 617 & 53 & 949 & 0.548 & 0.95 & $0.82-1.12$ \\
\hline Residence prior admission & in $\%$ & $n$ & in $\%$ & $n$ & & & \\
\hline At home, unassisted & 71 & 912 & 87 & 1558 & $<0.001$ & 0.36 & $0.3-0.44$ \\
\hline At home, assisted & 2 & 26 & 2 & 36 & $<0.001$ & 2.73 & $2.1-3.61$ \\
\hline Nursing home & 11 & 141 & 4 & 72 & $<0.001$ & 2.26 & $1.77-2.88$ \\
\hline Other hospital & 13 & 334 & 7 & 125 & 0.051 & 2.05 & $0.98-4.28$ \\
\hline Admission & in $\%$ & $n=$ & in $\%$ & $n=$ & & & \\
\hline Emergency & 67 & 861 & 47 & 842 & $<0.001$ & 2.24 & $1.9-2.64$ \\
\hline Elective & 29 & 373 & 49 & 26 & $<0.001$ & 0.4 & $0.34-0.48$ \\
\hline Length of stay in days ${ }^{a}$ & \multicolumn{2}{|c|}{$12.3,10.4 / 9,11$} & \multicolumn{2}{|c|}{$7.8,7.35 / 5,7$} & $<0.001$ & - & - \\
\hline Residence after hospital/delirium & in $\%$ & $n$ & in $\%$ & $n$ & & & \\
\hline At home, unassisted & 36 & 463 & 76 & 1361 & $<0.001$ & 0.17 & $0.15-0.21$ \\
\hline Deceased & 15 & 193 & 1 & 18 & $<0.001$ & 24.88 & $13.75-45.03$ \\
\hline Nursing home & 16 & 206 & 6 & 107 & $<0.001$ & 2.96 & $2.28-3.84$ \\
\hline Other hospital & 12 & 154 & 6 & 107 & $<0.001$ & 2.37 & $1.8-3.12$ \\
\hline Rehabilitation & 17 & 218 & 8 & 143 & $<0.001$ & 2.2 & $1.73-2.8$ \\
\hline
\end{tabular}

${ }^{a}$ Mean, standard deviation (SD)/median, interquartile range (IQR).

care units (ICUs). Higher overall complication rates, as evidenced by persistent cognitive decline, nursing home admissions, and mortality, have also been reported (Watt et al., 2019).

Life expectancy has increased; thus, the population of very old patients in healthcare facilities has also grown (Arai et al., 2012). Therefore, an in-depth knowledge of the prevalence rates of and risk factors for delirium is crucial for prevention, advance care planning, and improvements in healthcare professional and caregiver education. This comprehensive study evaluated the prevalence rates of and risk factors for dementia, as well as the medical characteristics of patients aged $\geq 80$ years with delirium.

\section{Methods}

\section{Patients and procedures}

Patient data from January 1 to December 31, 2014 were prospectively collected from a delirium detection initiative (DelirPath) at the local university hospital, a tertiary care center. A total of 39,442 patients were registered. The exclusion criteria were age $<18$ years, length of stay $<1$ day, and missing data. This resulted in 28,860 eligible patients, $3,076(10.7 \%)$ of whom were $\geq 80$ years old (Supplementary Figure 3 ). To determine the hospital departments, the primary diagnoses were linked to the corresponding departments.

\section{Measurements}

The 13-item Delirium Observation Screening scale (DOS) is validated to indicate delirium on the basis of the DSM-IV criteria
(Schuurmans et al., 2003; Gavinski et al., 2016). The items assess the following symptoms: 1, disturbance of consciousness; 2-4, attention; 5 and 6 , thought processes; 7 and 8 , orientation; 9, memory; 10, 11, and 13, psychomotor behavior; and 12, affect. The symptoms are rated on a scale of $0-1$ (nonexistent [0], sometimes to always existent [1], and unable to assess [-]), and the cutoff score for delirium is $\geq 3$ (Scheffer et al., 2011; Gavinski et al., 2016). The values were aggregated throughout recordings. This approach was found to be valid. It enabled the correct identification of $91 \%$ of delirium diagnoses, as determined by the consultation-liaison psychiatry service.

The Intensive Care Delirium Screening Checklist (ICDSC) comprises eight items based on the DSM-IV criteria. This twopoint (absent vs. present) screening instrument was designed for use in ICUs (Bergeron et al., 2001).

The electronic Patient Assessment - Acute Care (ePA-AC) is a daily administered nursing instrument. It is used to assess mobility, personal care and dressing, feeding, elimination, cognition and alertness, communication and interaction, sleeping, breathing, pain, pressure ulcers, and wounds (Hunstein, 2012).

\section{Delirium determination}

The DOS and ePA-AC were routinely administered to patients aged $\geq 80$ years upon admission on regular floors. The ICDSC was administered to patients in the ICU three times per day. All instruments (DOS, ICDSC, and ePA-AC) were administered by nurses who had completed courses that included literature research, case reports, and epidemiology. 
The determination of delirium was based on the DOS cut-off $(\geq 3)$, ICDSC cut-off $(\geq 4)$, DSM-5 criteria (disturbance in consciousness or attention), and the cognition-based construct based on the ePA-AC. This approach correctly identified $91 \%$ of the delirium diagnoses, as determined by the local team $(n=$ 9) consultation-liaison psychiatry service (Bode et al., 2019); thus, it was valid. Furthermore, this construct was tested against the validated DOS and ICDSC scales. It achieved almost perfect agreement (Cohen's $\kappa 0.83, p<0.001$ ).

This study was approved by the local ethics committee (KEK-ZH-Nr. 2012-0263). A waiver of informed consent was obtained from the committee. All reporting followed the Strengthening the Reporting of Observational Studies in Epidemiology statement (Vandenbroucke et al., 2014).

\section{Statistical methods}

Data analysis was performed with IBM SPSS Statistics for Windows, Version 25.0, and R version 3.5.0 for Windows. The descriptive characteristics were summarized on the basis of the parametric properties. Percentages are provided for the categorical variables, and means and standard deviations or medians and interquartile ranges are provided for the continuous variables. The Shapiro-Wilk test was used to determine the normality of the distribution of the data. For the continuous variables, the inter-group differences were assessed with the Student's $t$-test and Mann-Whitney $U$ test depending on their parametric properties, and for the categorical variables, Pearson's chi-squared test was performed.

In the first step, the delirium construct based on the DSM-5 was tested, and its agreement with the validated approach (DOS cut-off $\geq 3$ or ICDSC $\geq 4$ ) with Cohen's kappa coefficient was determined as a measure of concordance. Agreement was defined as follows: $0.61-0.80$, substantial agreement; $>0.80$, perfect agreement (Landis and Koch, 1977).

In the next step, the data were dichotomized by the presence or absence of delirium. They were then further categorized by managing department $(N=27)$. Simple logistic regressions were performed to determine the prevalence rates of delirium by medical department and medical characteristics, including the corresponding odds ratios (ORs) and confidence intervals. Two-tailed tests were used in the inferential statistical analysis, and the significance level $(\alpha)$ was set at $p<0.05$.

\section{Results}

\section{Characteristics of patients with delirium}

Of the 3,076 patients aged $\geq 80$ years, 1,285 (41.8\%) developed delirium (Table $1 \&$ Supplementary Figure 4 ). Gender was equally distributed across patients with and without delirium, with no significant effect on the development of delirium. The patients with delirium were less likely to have resided at home prior to admission $(\mathrm{OR}=0.36)$. They were more likely to require assisted living services $(\mathrm{OR}=2.73)$, to have been transferred from other hospitals $(\mathrm{OR}=2.05)$, or to be admitted as emergencies $(\mathrm{OR}=2.24)$.

Furthermore, these patients required prolonged hospitalization. The length of stay was twice that of patients without delirium, and they were more likely to require treatment in the ICU. At discharge, the patients with delirium had greater physical and functional impairment, as indicated by the greater need for care at other hospitals $(\mathrm{OR}=2.37)$ and rehabilitation centers
Table 2. Prevalence rates and odds ratios for developing delirium

\begin{tabular}{|c|c|c|c|c|}
\hline$N=3076(n / n)$ & $\%$ & $p$ & OR & $\mathrm{Cl}$ \\
\hline Angiology (30/157) & 19 & $<0.001$ & 1.47 & $0.38-2.81$ \\
\hline Ophthalmology (25/143) & 17 & $<0.001$ & 0.33 & $0.22-0.52$ \\
\hline Dermatology $(43 / 210)$ & 20 & $<0.001$ & 0.4 & $0.38-0.57$ \\
\hline Gastroenterology (19/64) & 30 & 0.184 & 0.69 & $0.4-1.19$ \\
\hline Geriatrics (6/23) & 26 & 0.251 & 0.58 & $0.23-1.48$ \\
\hline Gynecology (21/83) & 25 & 0.018 & 0.55 & $0.33-0.91$ \\
\hline Hematology (6/17) & 35 & 0.842 & 0.90 & $0.33-2.45$ \\
\hline Cardiac surgery $(78 / 128)$ & 60 & $<0.001$ & 2.72 & $1.89-3.92$ \\
\hline Cardiology (123/335) & 35 & 0.712 & 0.96 & $0.75-1.21$ \\
\hline Orofacial surgery $(15 / 38)$ & 40 & 0.813 & 1.08 & $0.56-2.08$ \\
\hline Internal medicine $(141 / 296)$ & 52 & $<0.001$ & 1.98 & $1.55-2.52$ \\
\hline Neurosurgery $(49 / 68)$ & 71 & $<0.001$ & 4.45 & $2.6-7.6$ \\
\hline Nephrology $(9 / 20)$ & 45 & 0.495 & 1.36 & $0.56-3.29$ \\
\hline Neurology (107/197) & 54 & $<0.001$ & 2.09 & $1.56-2.8$ \\
\hline Oncology (21/44) & 48 & 0.163 & 1.53 & $0.84-2.77$ \\
\hline Otorhinolaryngology (20/108) & 19 & $<0.001$ & 0.36 & $0.22-0.6$ \\
\hline Plastic surgery $(22 / 54)$ & 41 & 0.633 & 1.14 & $0.66-1.98$ \\
\hline Pneumonology (3/17) & 18 & 0.088 & 0.35 & $0.1-1.23$ \\
\hline Palliative care $(35 / 50)$ & 70 & $<0.001$ & 3.86 & $2.2-6.76$ \\
\hline Rheumatology $(8 / 52)$ & 15 & 0.001 & 0.30 & $0.14-0.63$ \\
\hline Thoracic surgery $(8 / 19)$ & 42 & 0.686 & 1.21 & $0.48-3.01$ \\
\hline Trauma $(115 / 269)$ & 43 & 0.067 & 1.27 & $0.98-1.64$ \\
\hline Urology (29/138) & 21 & $<0.001$ & 0.42 & $0.28-0.64$ \\
\hline Visceral surgery $(28 / 58)$ & 48 & 0.091 & 1.56 & $0.93-2.63$ \\
\hline $\begin{array}{l}\text { Intensive care unit (ICU) } \\
(196 / 267)\end{array}$ & 73 & $<0.001$ & 5.25 & $3.95-7$ \\
\hline $\begin{array}{l}\text { Intermediate care unit (IMC) } \\
(45 / 85)\end{array}$ & 53 & 0.006 & 1.82 & $1.18-2.81$ \\
\hline $\begin{array}{l}\text { Neurological intermediate } \\
\text { care (stroke) }(83 / 136)\end{array}$ & 61 & $<0.001$ & 2.9 & $2.7-3.86$ \\
\hline
\end{tabular}

OR, odds ratio; $\mathrm{Cl}$, confidence interval.

$(\mathrm{OR}=2.2)$ rather than the capability to return to their own residences $(\mathrm{OR}=0.17)$. They also had more severe illness and a higher mortality risk during their stay $(\mathrm{OR}=24.88)$.

\section{Prevalence rates of delirium by medical department}

The highest delirium prevalence rates were found in the intensive medical services [ICU, 73\%; stroke unit, 61\%; and immediate care units (IMCs), 53\%; Table 2; Figures 1 and 2]. High prevalence rates were also noted in the specialist departments for patients with brain disease (neurosurgery, 71\%; neurology, 54\%) and advanced and terminal illness (palliative care, 70\%). Conversely, in rheumatology, the prevalence and risk were low $(15 \%, \mathrm{OR}=$ $0.3)$. 


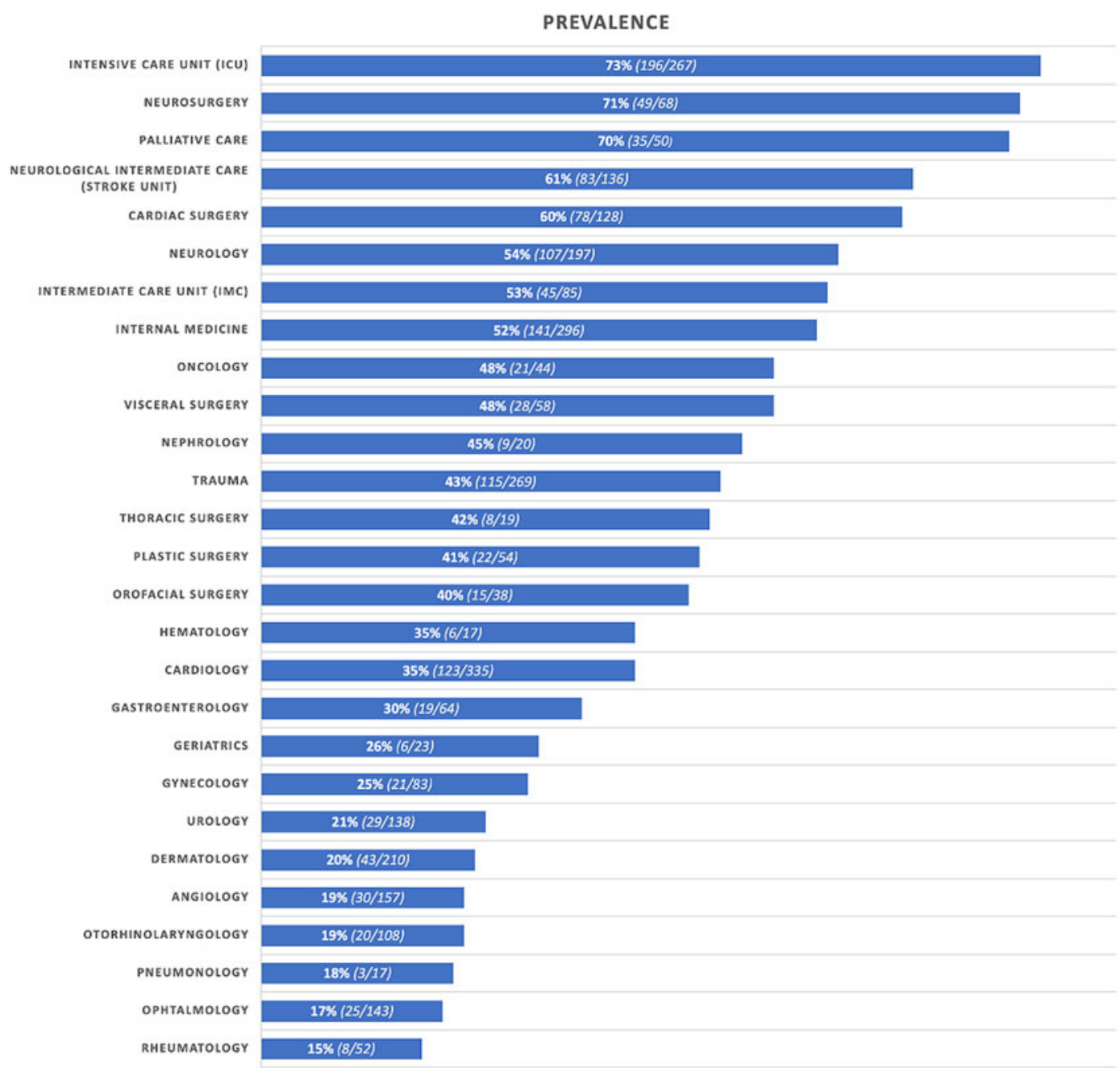

Fig. 1. Prevalence rates of delirium in 27 medical departments.

\section{Discussion \\ Main findings}

Very old patients, those aged $\geq 80$ years, are an emerging patient population. However, much less data about delirium prevalence rates, risk factors, and further medical characteristics are available for these patients than for the elderly aged $\geq 65$ years. This study of the occurrence of delirium in a population of 3,076 hospitalized patients aged $\geq 80$ years is the largest to date.

The overall prevalence of delirium in patients aged $\geq 80$ years was high: $41.8 \%$. These patients were more likely to be admitted via emergency referrals and from facilities, such as nursing homes and assisted living housing. The length of hospital stay was twice that for other patients. Patients with delirium were less likely to return home $(\mathrm{OR}=0.17)$ and more likely to be admitted to facilities, that is, other hospitals ( $\mathrm{OR}=2.37)$, rehabilitation centers $(\mathrm{OR}=2.2)$, or assisted living $(\mathrm{OR}=2.96)$. The mortality risk increased considerably $(\mathrm{OR}=24.88)$.

There were considerable variations in delirium prevalence by medical department. For more than one-third (8 of 27) of the departments, the prevalence rate exceeded $50 \%$ (ICU, 73\%; neurosurgery, $71 \%$; palliative care, $70 \%$; stroke unit, $61 \%$; cardiac surgery, 60\%; neurology, 54\%; IMCs, 53\%; and internal medicine, $52 \%$ ). Interestingly, these services were associated with brain, heart, or severe infectious diseases. This confirms the findings of previous studies regarding the increased risk for these patients to develop delirium (Khan et al., 2019; Mossello et al., 2019).

Few studies have discussed the prevalence rates of delirium in patients aged $\geq 80$ years, and comparisons are few (Mazzola et al., 2015; Eide et al., 2016; Kotfis et al., 2018). Thus, studies describing the prevalence rates in patients aged $\geq 65$ years were considered. Men have been found to be at a higher risk for developing delirium (1) and other diseases (Angele et al., 2014; Jacob et al., 2019). This also applies to patients aged $\geq 65$ years. In those aged $\geq 80$ years, being male was not a risk factor. The reasons might be life expectancy and sociodemographic distribution.

The role of the residence prior to admission has not yet been studied in detail; however, patients admitted from assisted living facilities have been found to have worse outcomes (Friedman et al., 2008; de Saint-Hubert et al., 2009). Assisted living residency housing prior to admission has been found to be a predisposing factor in delirium $(\mathrm{OR}=2.72)$, and independent living has been associated with a low risk $(\mathrm{OR}=0.36)$. Similarly, in the present study, very old patients with delirium were almost twice as likely to be admitted from nursing homes $(\mathrm{OR}=2.2)$ than from their own residences. Assisted living has been found to be associated with higher morbidity (Kosar et al., 2017; Vossius et al., 2018)' and multimorbidity (Inouye, 2018). This suggests that assisted 


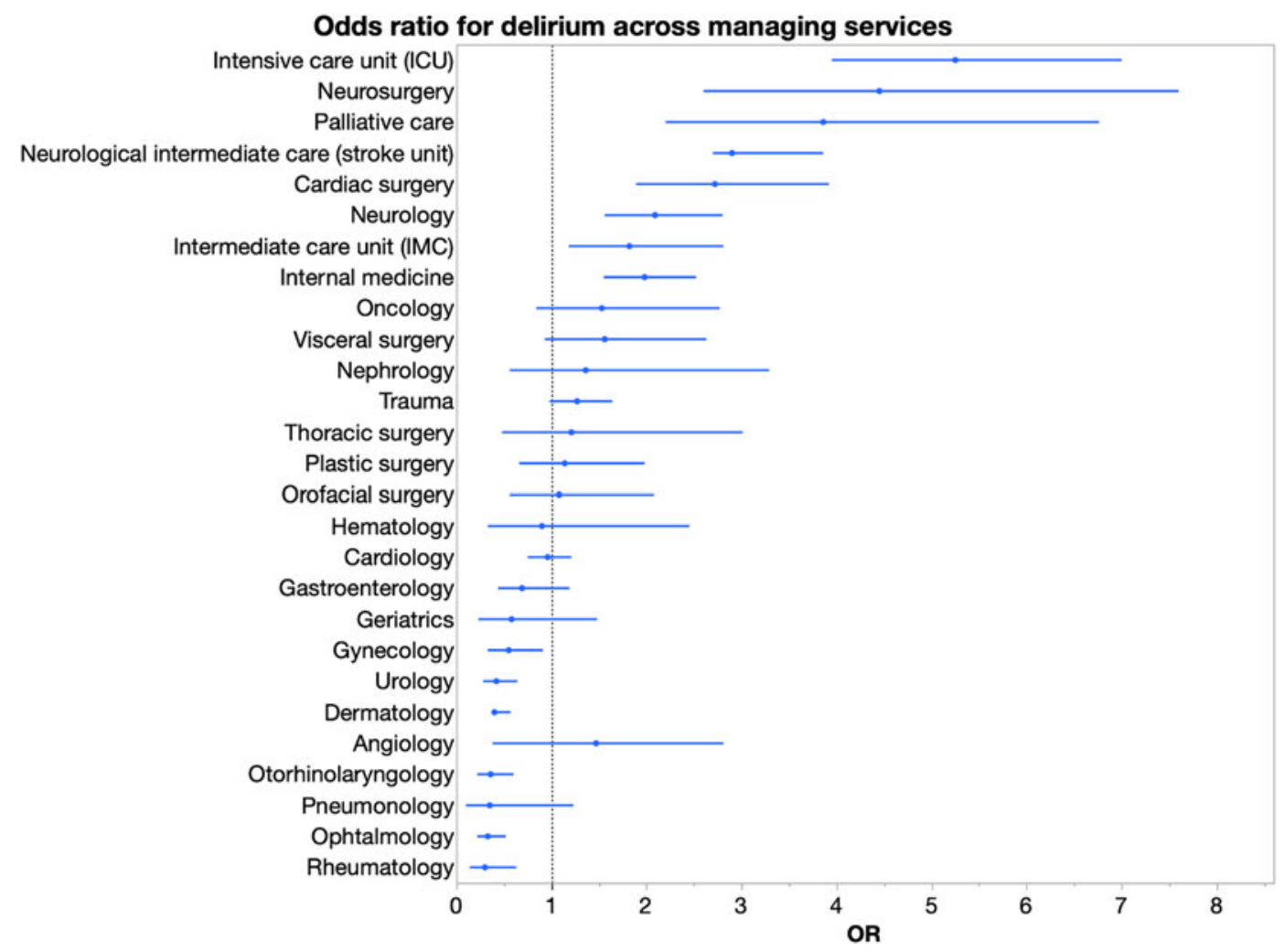

Fig. 2. Risk of developing delirium: Odds ratios (OR) and confidential intervals (Cls) for 27 medical departments.

living might be a predisposing factor for delirium. This finding could enhance awareness of delirium in very old individuals, especially in emergent situations in which it is under-detected (Elie et al., 2000).

Emergency admission was a substantial risk factor for developing delirium $(\mathrm{OR}=2.24)$. Patients in the emergency room often suffer from multimorbidity involving acute decompensated diseases (McPhail, 2016); thus, the occurrence of delirium might be indicative or predictive of disease severity and trajectory. This was supported by the prolonged hospitalization. The average hospital stay of patients with delirium was twice as long as that of other patients (12.3 vs. 7.8 days). Their mortality risk was substantially higher $(\mathrm{OR}=24.88)$. It was also considerably higher than that found in prior studies (Mazzola et al., 2015). Regarding the increased mortality risk resulting from delirium, it was not methodologically possible to distinguish the incidence of suicide. This is relevant because the prevalence of suicide as a consequence of neuropsychiatric disease has been underestimated (Arciniegas and Anderson, 2002; Coughlin and Sher, 2013; Costanza et al., 2015, 2020a, 2020b; Eliasen et al., 2018).

A highly relevant clinical finding was the prevalence of delirium in the very old, that is, patients aged $\geq 80$ years. The prevalence in the general population was found to reach 20\% (Evans et al., 2016); however, it was twice as high (41.8\%) in the very old. Thus, two out of five patients aged $>80$ years developed delirium during hospitalization. The prevalence rates of delirium in patients aged $\geq 80$ years by medical department were found to be highest in the ICUs and IMCs. Previous studies on ICUs have found wide variations $(7-89 \%)$ in the prevalence rates of dementia. For patients aged $\geq 80$ years, the rates increased to $53-73 \%$.

\section{Limitations}

The large sample size, which included consecutive admissions over 1 year, is a strength of this study. There are a few limitations. The etiologies of delirium (e.g., previous dementia, sepsis, or brain tumor) were not included in this analysis. The patient sample was from a tertiary care center; thus, replication is needed to facilitate generalizability to other healthcare settings.

\section{Implications}

Unlike previous studies on elderly individuals, this study has comprehensively described the prevalence rates of delirium in a large sample. Thus, the findings are based on the data for patients aged 80-102 years in 27 medical departments. With an aging society (7), studies need to focus on the growing number of older patients among hospitalized populations. The findings of the present study indicate that delirium was frequently diagnosed in those aged $\geq 80$ years. Specifically, patients admitted as emergencies or from assisted living housing were hospitalized longer. In addition, they were more likely to die before discharge or to require assisted living housing upon discharge. These findings could inform advanced care planning. They also confirm those of previous studies regarding the need to screen patients aged $\geq 80$ years, and even those who are younger, for delirium.

\section{Conclusion}

Delirium occurs frequently in individuals aged $>80$ years. It is likely underdiagnosed; however, it is an indicator for the subsequent loss of independence and, ultimately, mortality. This study is the largest to assess the prevalence and medical 
trajectories of very old patients with delirium. This study extends the limited knowledge about delirium, a life-threating condition, in an increasingly aging society. These results also suggest that the accurate detection of delirium in patients aged $>80$ years could be achieved with the nursing instruments used in daily practice. Studies on delirium outcomes are required to determine the potential of the approach adopted in this study for maintaining the independence of and lowering the morbidity and mortality rates in this growing population.

Supplementary material. The supplementary material for this article can be found at https://doi.org/10.1017/S1478951521001814.

Acknowledgment. We thank the clinical staff who made this study possible.

Funding. This work was supported by the clinician scientist program of the medical faculty of the local university (Program Number: 45800).

Conflict of interest. The authors declare that they have no conflict of interest.

\section{References}

American Psychiatric Association (2013) Diagnostic and Statistical Manual of Mental Disorders, 5th ed. Arlington: American Psychiatric Association.

Angele MK, Pratschke S, Hubbard WJ, et al. (2014) Gender differences in sepsis. Virulence 5(1), 12-19. doi:10.4161/viru.26982

Arai H, Ouchi Y, Yokode M, et al. (2012) Toward the realization of a better aged society: Messages from gerontology and geriatrics. Geriatrics \& Gerontology International 12(1), 16-22. doi:10.1111/j.1447-0594.2011.00776.x

Arciniegas DB and Anderson CA (2002) Suicide in neurologic illness. Current Treatment Options in Neurology 4(6), 457-468. doi:10.1007/ s11940-002-0013-5

Bellelli G, Morandi A, Di Santo SG, et al. (2016) "Delirium Day": A nationwide point prevalence study of delirium in older hospitalized patients using an easy standardized diagnostic tool. BMC Medicine 14, 106. doi:10.1186/ s12916-016-0649-8

Bergeron N, Dubois MJ, Dumont M, et al. (2001) Intensive care delirium screening checklist: Evaluation of a new screening tool. Intensive Care Medicine 27(5), 859-864.

Bode L, Isler F, Fuchs S, et al. (2019) The utility of nursing instruments for daily screening for delirium: Delirium causes substantial functional impairment. Palliative \& Supportive Care, 1-8. doi:10.1017/S1478951519001019

Costanza A, Baertschi M, Weber K, et al. (2015) Neurological diseases and suicide: From neurobiology to hopelessness. Revue Medicale Suisse 11 (461), 402-405.

Costanza A, Amerio A, Aguglia A, et al. (2020a) When sick brain and hopelessness meet: Some matters on suicidality in the neurological patient. CNS \& Neurological Disorders Drug Targets. doi:10.2174/ 1871527319666200611130804

Costanza A, Amerio A, Radomska M, et al. (2020b) Suicidality assessment of the elderly with physical illness in the emergency department. Frontiers in Psychiatry 11. doi:10.3389/fpsyt.2020.558974

Coughlin SS and Sher L (2013) Suicidal behavior and neurological illnesses. Journal of Depression \& Anxiety Suppl 9(1). doi:10.4172/2167-1044.S9-001

de Saint-Hubert M, Schoevaerdts D, Poulain G, et al. (2009) Risk factors predicting later functional decline in older hospitalized patients. Acta Clinica Belgica 64(3), 187-194. doi:10.1179/acb.2009.034

Eide LSP, Ranhoff AH, Fridlund B, et al. (2016) Delirium as a predictor of physical and cognitive function in individuals aged 80 and older after transcatheter aortic valve implantation or surgical aortic valve replacement. Journal of the American Geriatrics Society 64(6), 1178-1186. doi:10.1111/ jgs. 14165

Eliasen A, Dalhoff KP and Horwitz H (2018) Neurological diseases and risk of suicide attempt: A case-control study. Journal of Neurology 265(6), 13031309. doi:10.1007/s00415-018-8837-4
Elie M, Rousseau F, Cole M, et al. (2000) Prevalence and detection of delirium in elderly emergency department patients. CMAJ: Canadian Medical Association Journal=Journal de l'Association Medicale Canadienne 163(8), 977-981.

Evans AS, Weiner MM, Arora RC, et al. (2016) Current approach to diagnosis and treatment of delirium after cardiac surgery. Annals of Cardiac Anaesthesia 19(2), 328-337. doi:10.4103/0971-9784.179634

Friedman SM, Mendelson DA, Bingham KW, et al. (2008) Hazards of hospitalization: Residence prior to admission predicts outcomes. The Gerontologist 48(4), 537-541. doi:10.1093/geront/48.4.537

Gavinski K, Carnahan R and Weckmann M (2016) Validation of the delirium observation screening scale (DOS) in a hospitalized older population. Journal of Hospital Medicine 11(7), 494-497. doi:10.1002/jhm.2580

Hunstein D (2012) Ergebnisorientiertes PflegeAssessment Acute-Care. Germany: EPA-Competence Center, pp. 1-72.

Inouye SK (2018) Delirium-A framework to improve acute care for older persons. Journal of the American Geriatrics Society 66(3), 446-451. doi:10.1111/jgs. 15296

Inouye SK, Westendorp RG, Saczynski JS, et al. (2014) Delirium in elderly people-Authors' reply. Lancet 383(9934), 2045. doi:10.1016/S0140-6736 (14)60994-6

Jacob L, Tanislav C and Kostev K (2019) Long-term risk of stroke and its predictors in transient ischemic attack patients in Germany. European Journal of Neurology. doi:10.1111/ene.14136

Khan BA, Perkins AJ, Prasad NK, et al. (2019) Biomarkers of delirium duration and delirium severity in the ICU. Critical Care Medicine. doi:10.1097/ CCM.0000000000004139

Kosar CM, Thomas KS, Inouye SK, et al. (2017) Delirium during postacute nursing home admission and risk for adverse outcomes. Journal of the American Geriatrics Society 65(7), 1470-1475. doi:10.1111/ jgs. 14823

Kotfis K, Szylinska A, Listewnik M, et al. (2018) Early delirium after cardiac surgery: An analysis of incidence and risk factors in elderly ( $>/=65$ years) and very elderly ( $>/=80$ years) patients. Clinical Interventions in Aging 13, 1061-1070. doi:10.2147/CIA.S166909

Landis JR and Koch GG (1977) The measurement of observer agreement for categorical data. Biometrics 33(1), 159-174.

Mazzola P, Bellelli G, Broggini V, et al. (2015) Postoperative delirium and pre-fracture disability predict 6-month mortality among the oldest old hip fracture patients. Aging Clinical and Experimental Research 27(1), 53 60. doi:10.1007/s40520-014-0242-y

McPhail SM (2016) Multimorbidity in chronic disease: Impact on health care resources and costs. Risk Management and Healthcare Policy 9, 143-156. doi:10.2147/RMHP.S97248

Mossello E, Baroncini C, Pecorella L, et al. (2019) Predictors and prognosis of delirium among older subjects in cardiac intensive care unit: Focus on potentially preventable forms. European Heart Journal. Acute Cardiovascular Care. doi:10.1177/2048872619882359

Saxena S and Lawley D (2009) Delirium in the elderly: A clinical review. Postgraduate Medical Journal 85(1006), 405-413. doi:10.1136/ pgmj.2008.072025

Scheffer AC, van Munster BC, Schuurmans MJ, et al. (2011) Assessing severity of delirium by the delirium observation screening scale International Journal of Geriatric Psychiatry 26(3), 284-291. doi:10.1002/ gps. 2526

Schuurmans MJ, Shortridge-Baggett LM and Duursma SA (2003) The delirium observation screening scale: A screening instrument for delirium. Research and Theory for Nursing Practice 17(1), 31-50.

Vandenbroucke JP, von Elm E, Altman DG, et al. (2014) Strengthening the reporting of observational studies in epidemiology (STROBE): Explanation and elaboration. International Journal of Surgery 12(12), 1500-1524. doi:10.1016/j.ijsu.2014.07.014

Vossius C, Selbæk G, Šaltytė Benth J, et al. (2018) Mortality in nursing home residents: A longitudinal study over three years. PLoS One 13(9). doi:10.1371/journal.pone. 0203480

Watt CL, Momoli F, Ansari MT, et al. (2019) The incidence and prevalence of delirium across palliative care settings: A systematic review. Palliative Medicine 33(8), 865-877. doi:10.1177/0269216319854944 